\title{
Towards a better understanding of squeezing potential in hard rock mines
}

\author{
F. Mercier-Langevin Agnico-Eagle Mines Ltd, Canada \\ J. Hadjigeorgiou University of Toronto, Canada
}

\begin{abstract}
A significant number of underground hard rock mines have to struggle to maintain and keep operational excavations in squeezing ground conditions. This can often result in considerable investment in rock reinforcement and support and in time-consuming and possibly hazardous scaling and rehabilitation. The LaRonde Mine in Canada has reported squeezing conditions in geological conditions ranging from weak to hard rock. This paper reports on the development of a 'Hard Rock Squeezing Index' based on case studies reported from several mining operations and calibrated based on in situ observations from the LaRonde Mine. The Hard Rock Squeezing Index is based on the foliation spacing of the rock mass and the stress to intact rock strength ratio. This index further incorporates the influence of excavation orientation with regards to structure in order to provide an indicator of squeezing potential.
\end{abstract}

\section{Introduction}

Large scale deformations, often referred to as squeezing ground conditions, are typically associated with soft and/or weak rock types in both tunnelling and mining. Nevertheless, large scale deformations are also observed in hard rock if both structure and high stress are present.

The majority of documented case studies in squeezing ground conditions are from the tunnelling industry, for example Steiner (1996), Aydan et al. (1996), Barla et al. (2007). Kontogianni et al. (2004) analysed deformation records of several tunnels in good quality rock and concluded that it was possible to predict the eventual deformations based on elasto-plastic numerical models. Tunnels excavated in weak rock, however, resulted in deformation several times higher than predicted by the design models and exceeded the critical $2 \%$ strain boundary. In the majority of tunnelling case studies excessive deformation was a main factor controlling the failure and cost-effectiveness of underground excavations.

A significant number of hard rock mines in operation around the world have to manage problems associated with squeezing conditions. For these mines, maintaining excavations open and operational is difficult and often results in considerable investment in rock reinforcement and support but also in time-consuming and sometimes hazardous scaling and rehabilitation operations. Large scale deformations are a major concern during the construction and maintenance of underground mining excavations. Squeezing conditions are caused by a variety of failure mechanisms but are typically characterised by reduction in the cross sectional area of an excavation as a result of a combination of induced stresses and relatively weak material properties, Potvin and Hadjigeorgiou (2008). There is limited information of large scale numerical modelling of squeezing in underground mines. Beck et al. (2010) report some success in simulating extreme tunnel closure using a multi-scale approach.

There are fewer documented case studies of squeezing ground condition in mining, as opposed to tunnelling. Nevertheless, as mines operate at greater depth they face additional challenges in maintaining drifts operational under squeezing rock conditions. Potvin and Hadjigeorgiou (2008) report the observations of an international task force on several mines that have to operate in squeezing ground conditions. In Canada, Agnico-Eagle's LaRonde Mine reported by Mercier-Langevin and Turcotte (2007a, 2007b), Casa Berardi (Aurizon), Lapa (Agnico-Eagle) and Myra Falls (Breakwater Resources) have to manage significant levels of drift closure. In Australia, BHP's Perseverance Mine, Maggie Hays and Black Swan (Norilsk Nickel) and Agnew Gold Mine (Gold Fields) among others, report various degrees of squeezing ground. A common 
observation is that in most cases it is very expensive to prevent drive closure and floor heave, Tyler and Werner (2004); Mercier-Langevin and Turcotte (2007a).

The majority of tools used to estimate the susceptibility of excavations to closure are based on empirical data from civil engineering tunnels in weak rock. Rock masses composed of weak rock tend to behave in a nearly isotropic fashion even when highly foliated. Excavations in foliated hard rock are more susceptible to anisotropic behaviour. Empirical evidence at LaRonde demonstrated that the angle of interception of an excavation with regards to dominant structure has a significant influence on the level of observed closure.

This paper reports on the development of a Hard Rock Squeezing Index based on observations from LaRonde, supported by case studies reported from several mines experiencing squeezing ground around the world. The Hard Rock Squeezing Index is based on the spacing of structural features in the rock mass and the stress to strength of intact rock ratio. The index further incorporates the influence of excavation orientation with regards to structure. This index is intended as a preliminary indicator of the squeezing potential of a rock mass and as such can be used to develop different design and support strategies.

\section{Squeezing ground}

Tunnelling in difficult mining conditions is often associated with swelling and squeezing ground conditions. Einstein (1996) suggests that swelling in tunnels is the time dependent volume increase of the ground, leading to inward movement of the tunnel perimeter, and squeezing is the time dependent shearing of the ground, leading to inward movement of the tunnel perimeter.

Swelling is the process of closure of the tunnel due to an increase in the volume of the surrounding rock mass due to adsorption of water. Swelling mechanisms can be quite complex and can include mechanical, osmotic and inter crystalline processes that can also interact with each other. A necessary condition is the presence of clay minerals, for example montmorillonite, smectite, etc. The potential for swelling in tunnels can be determined from free swell tests, Atterberg limit, grain size analyses to determine the clay content and $\mathrm{X}$-ray diffraction to determine the type of clay minerals present, Klein (2001).

A review of theoretical criteria for squeezing ground has already been proposed by Potvin and Hadjigeorgiou (2008). In a mining context there is often an emphasis on empirical rock mass classification systems. The limitation of using a rock mass classification rating may not necessarily be a good indicator of squeezing. For example Singh et al. (1992) suggested that squeezing rock in tunnelling can occur for depth $\mathrm{H}>350 \mathrm{Q}^{1 / 3}$ where $\mathrm{H}$ is the overburden in (m) and Q is the Tunnelling index proposed by Barton et al. (1974). It can be argued that the same Q rating can be arrived at for quite different conditions. Furthermore, despite the clear trends of stress increasing with depth the high variability of horizontal stress can result in significant variations in different parts of the world. Perhaps a better approach in predicting squeezing potential is to recognise that the $\mathrm{Q}$ system identifies squeezing rock as "plastic flow of incompetent rock under the influence of high pressure and is part of the stress reduction factor (SRF). In the Q system an SRF rating within 5-10 suggests 'mild squeezing pressure' and a 'heavy squeezing rock pressure' has a SRF between $10-20$.

It is generally accepted that squeezing rock is recognised by the influence of stress acting on a rock or a rock mass. Nevertheless, there are some inconsistencies in the literature, and a certain degree of overlap, of what constitutes a weak, soft rock or rock mass. Wang et al. (2000) refer to the ISRM and Johnston (1993) to define a soft rock as a geotechnical material with a uniaxial compressive strength in the range of $0.5-0.25 \mathrm{MPa}$. They suggest that soft rock is comprised of extremely weak rock, very weak rock and weak rock. A different approach is used by Russo (1994) whereby 'weak rock' is used to group together all rocks, including intact and rock mass of low strength that includes soft rocks, weathered rocks, intensely fractured rock masses etc. Russo (1994) also employs the terms complex rocks and poor rock mass (poor mechanical quality). Hoek and Marinos (2000) use the uniaxial compressive strength $\left(\sigma_{\mathrm{cm}}\right)$ of the rock mass and 'E' (the deformation modulus of the rock mass) to identify potential tunnel squeezing problems in heterogeneous rock masses. Klein (2001) suggests that the strength of weak rocks is influenced by the porosity of the rocks. This is particularly true in sedimentary rocks such as sandstone, siltstone, shale, mudstone and some volcanic rocks such as tuff, agglomerate and breccia. Klein (2001) suggests that a weak rock can be any rock type that is weathered and altered. 
A convenient way to investigate squeezing in rock is to assume that the behaviour of weak intact rock is very similar to a heavily fractured rock mass. In other words both $\sigma_{\mathrm{c}}$ and $\sigma_{\mathrm{cm}}$ are low. For example, large scale geological features compared to excavation size are associated with squeezing ground conditions. Struthers et al. (2000) refer to the importance of weak shear zones on the observed deformation at the Perseverance Mine in Western Australia. Yassaghi and Salari-Rad (2005) concluded that squeezing rock conditions were due to the reduced strength of the rock mass at the contact zone of an andesitic-basaltic body and tuff country rocks in the Taloun tunnels in Iran. Potvin and Hadjigeorgiou (2008) report on the influence of major structures on observed deformations at mines in Australia and Canada.

On the other hand, rock masses defined by anisotropy such as bedding planes, schistosity etc., behave in a very different manner than intact rock when subjected to high stress conditions. In deep and high stress mines, squeezing conditions are caused by the presence of foliation and the orientation of the drift with respect to this foliation. In the first place as fracture spacing decreases, the observed deformation increases. This was recognised by Potvin and Hadjigeorgiou (2008) during site visits, demonstrated using analytical buckling solutions by Kazakidis (2002), physical modelling by Lin et al. (1984) and by numerical studies by Beer et al. (1981) and Hsu et al. (2004). Drift or tunnel orientation with respect to the rock structure also has a considerable influence on the resulting squeezing rate and the magnitude of observed closure. Examples from civil engineering tunnelling projects are provided by Lin et al. (1984), Steiner (1996), Barla (2002), Panet (1996). Beck and Sandy (2003) report of squeezing ground conditions in several Western Australia underground mines. This was prominent in drives parallel to the foliation, particularly where the major principal stress was orthogonal to the excavations. At LaRonde, Mercier-Langevin and Turcotte (2007a) reported the implementation of a modified level layout that minimised deformations in the main haulage drifts. This was achieved by maximising development at a favourable angle with respect to foliation. Although this mine modification resulted in an increase in development per level, the added cost was offset by a significant reduction in required reconditioning work (and associated delays).

\subsection{Squeezing in hard rock mines}

Potvin and Hadjigeorgiou (2008) report that most mines experiencing squeezing ground conditions are characterised by prominent structural features such as: a dominant fracture set; intense foliation or a shear zone; and high stresses. Furthermore, the host rock type, where squeezing was most dominant, was characterised by relatively weak intact rock strength (less than $60 \mathrm{MPa}$ ). Although these two conditions appear to be necessary the degree of squeezing has been observed to increase in the presence of localised alteration such as mica, chlorite, and tochilinite. Alteration results in much weaker rock strength. Another contributing factor to large scale deformation is orienting the excavation parallel to the dominant structural feature (foliation, bedding, etc.).

The thickness of foliation layers has a direct impact on the rate of convergence, Potvin and Hadjigeorgiou (2008). In three mines thin foliation layers led to heavy squeezing while in other two mines thicker layers resulted in moderate squeezing. Table 1 summarises the characteristics that resulted into two different degrees of squeezing.

Table 1 Categories of squeezing ground based on foliation thickness (after Potvin and Hadjigeorgiou, 2008)

\begin{tabular}{lll}
\hline Category & Category $\mathbf{1}$ & Category 2 \\
\hline Squeezing level & Heavy squeezing & Moderate squeezing \\
Rock layers & Thin (10s of millimetres) & Thick (10s of centimetres) \\
Uniaxial compressive strength & Approximately $10 \mathrm{MPa}$ & Approximately $50 \mathrm{MPa}$ \\
$\begin{array}{l}\text { Maximum rate of } \\
\text { convergence }\end{array}$ & $100 \mathrm{~s}$ of mm per month & $10 \mathrm{~s} \mathrm{~mm}$ per month \\
Depth of broken rock mass & Up to $6 \mathrm{~m}$ & Up to $3 \mathrm{~m}$ \\
\hline
\end{tabular}

LaRonde poses an interesting conundrum, however, as it exhibits heavy squeezing normally associated with Category 1 even though, based on the rock properties (UCS and rock layer thickness) it would be expected to 
result in moderate squeezing, Category 2. It would appear that the considerably higher stresses at depth, at LaRonde, compensate for the stronger rock.

This paper draws from case studies reported from several mining operations and calibrated based on in situ observations from LaRonde to develop a tool to predict squeezing rock conditions. The major advantage in the development and calibration of the Hard Rock Squeezing Index has been access to several sites at LaRonde of varying degrees of squeezing. The field observations are presented in Section 3.

\section{Field observations at LaRonde Mine}

Agnico-Eagle Mines Ltd. has been operating the LaRonde Mine located near the village of Preissac in Northern Quebec since 1988. The LaRonde orebody is a world-class Au-Ag-Cu-Zn massive sulphide lenses complex with reserves extending from surface down to 3,110 meters and still open at depth. Over 600 employees are operating the complex, for an average production of 7,200 tonnes per day. The 2,240 meter deep Penna shaft is used to hoist the ore. Production is ongoing between level $122(1,220$ meters below surface) and level 245 (2,450 meters below surface). Figure 1 presents a longitudinal view of the LaRonde orebody. The mine is currently undergoing an expansion phase that will enable access to reserves as deep as 3,110 meters below surface via an $800 \mathrm{~m}$ winze.

The mine has been dealing with squeezing ground for years. As mining activities progressed deeper, however, excessive closure and rehabilitation of haulage drifts became a major concern. Mercier-Langevin and Turcotte (2007a) reported on severe squeezing in haulage drifts in the lower mine, as illustrated in Figure 2. The failure mode was identified as sidewall buckling of foliation planes dipping roughly 80 degrees to the south (striking parallel to the orebody). In some areas of the mine, total wall convergence can be in excess of a metre and fractures extend as deep as $6 \mathrm{~m}$ into the rock mass. 


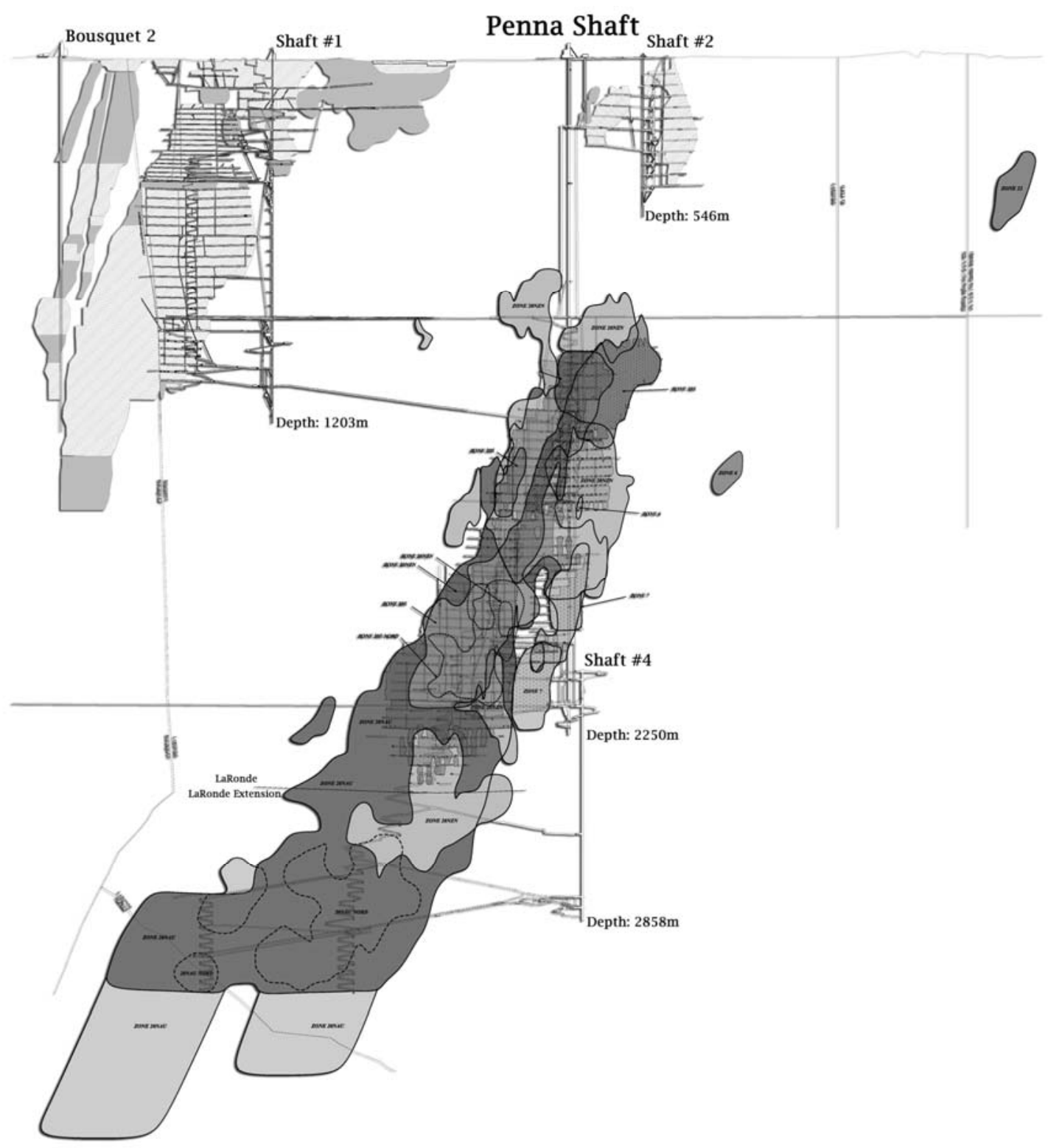

\section{Figure 1 Longitudinal view of the LaRonde Mine}

The mine has tried a range of support strategies in order to contain the observed deformations. MercierLangevin and Turcotte (2007b) trace the evolution of reinforcement units employed at LaRonde. Resin grouted bolts were too stiff and failed early in the deformation process. The mine had some success with friction bolts in highly fractured conditions. Nevertheless, it has been observed that their capacity to accommodate large deformations is limited when they are subjected to shear loads. At the stage when buckling of foliation reaches a certain critical level friction bolts tend to 'lock up'. As the walls further deform the bolts are subjected to rapid loads and consequently fail, most often at the collar of the bolt. Due to their ease of installation and relatively low costs Split set bolts are still used widely but either stronger support (hybrid bolts) will be installed shortly thereafter to supplement them, or they will be replaced during reconditioning. At LaRonde, both Swellex and Super Swellex bolts have performed well when installed in failed ground but have been less successful in withstanding shear loads. The mine has had limited success with the use of cement grouted cable bolts, yielding cable bolts and modified cone bolts in squeezing ground.

Since 2007, LaRonde has had good success with the use of hybrid bolts in squeezing ground, MercierLangevin and Turcotte (2007b). The hybrid bolt is essentially a resin bar installed within a friction bolt. The hybrid bolt has outperformed all other bolts used under squeezing ground conditions at LaRonde. 


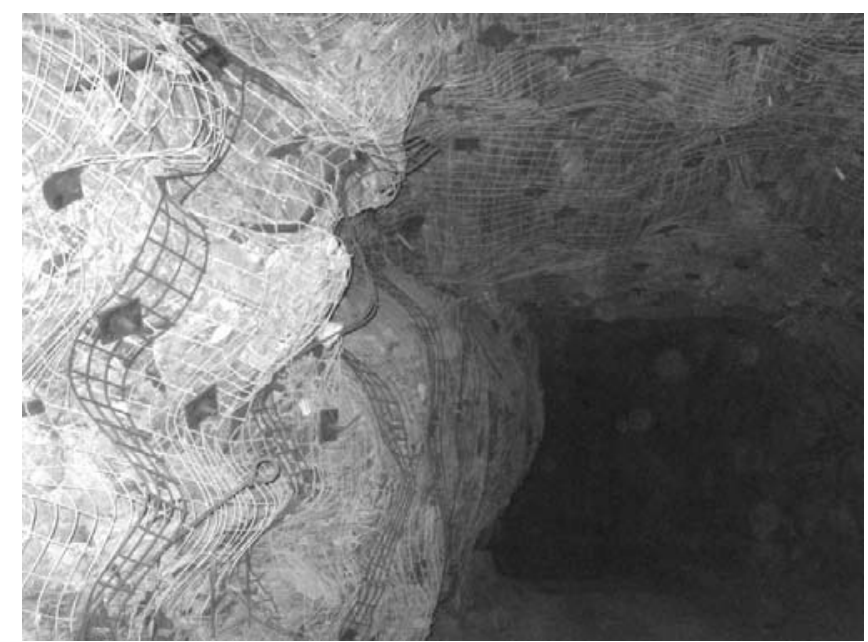

Figure 2 Squeezing in haulage drift at LaRonde Mine

\subsection{Foliation spacing}

The presence of structure is arguably the single most important factor to the onset of squeezing in hard rock. There is a clear trend in literature linking foliation (or bedding planes) spacing with squeezing rates and severity. Hoek and Marinos (2000) recognise that the behaviour of bedded rock masses is strongly anisotropic and is controlled by the fact that the bedding planes are an order of magnitude weaker than any other feature.

This influence of foliation spacing is supported by field observations at LaRonde. Figure 3 shows three different headings developed at a shallow angle to foliation, under similar stress conditions in the same rock type (felsic tuff). The only significant difference in all three cases is the variation in foliation spacing. The drift outline varies accordingly, exhibiting a behaviour ranging from minor to severe squeezing.

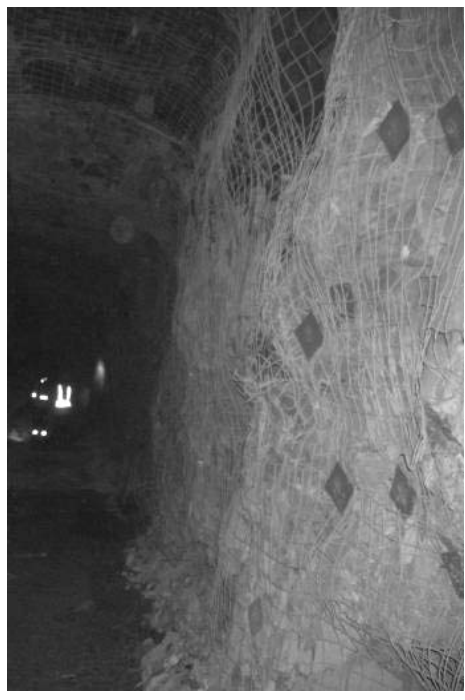

(a)

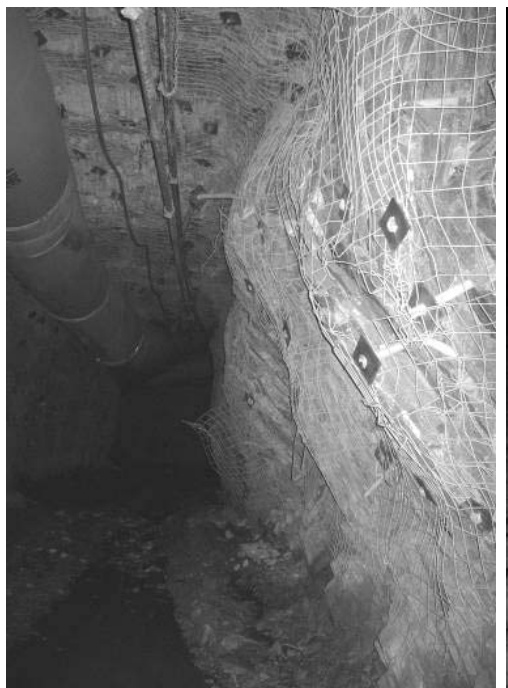

(b)

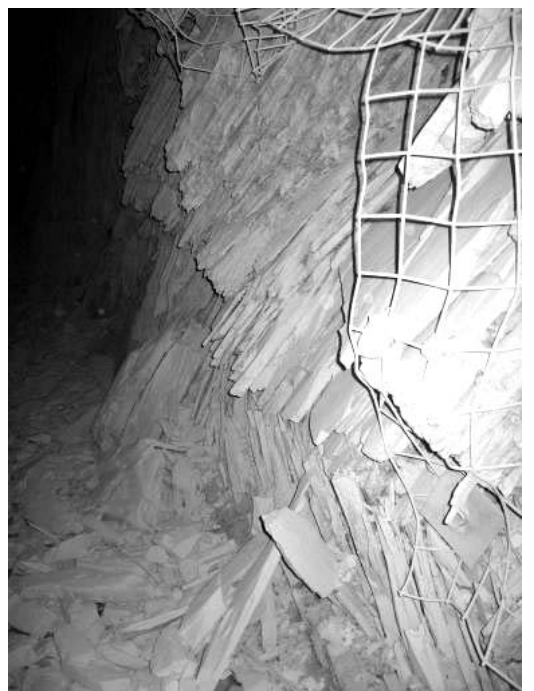

(c)

Figure 3 Variations in squeezing severity at locations less than $200 \mathrm{~m}$ apart at 2,300 $\mathrm{m}$ depth: (a) thick layers $(20-40 \mathrm{~cm})$ - minor squeezing; (b) intermediate thickness layers $(10-20 \mathrm{~cm})$ moderate squeezing; (c) thin layers $(2-10 \mathrm{~cm})$ - severe squeezing

\subsection{Stress to intact rock strength ratio}

In most isotropic hard rock masses, it is believed that on its own, a high stress to intact rock strength ratio is not conducive to the development of squeezing ground conditions. Such is not the case for highly foliated 
rock masses. In those particular conditions, this ratio basically defines the proneness of individual layers to buckling failure.

At LaRonde, the severity of squeezing can be affected either by an increase in stress or by a decrease in rock strength. In otherwise similar conditions the level of squeezing can vary dramatically depending on stress magnitude, Figure 4. For example, for identical rock types and excavation geometry, headings in the upper mine (where stresses are lower) are less prone to squeezing than headings in the lower mine (where stresses are higher). Conversely, intact rock strength can also vary quite significantly at the mine depending on the degree of alteration it displays. However, this alteration process (deep-seated sericitic alteration) also has a significant effect on joint strength. Consequently, it is difficult to distinguish the effects of alteration on intact rock from those on the rock mass as a whole.
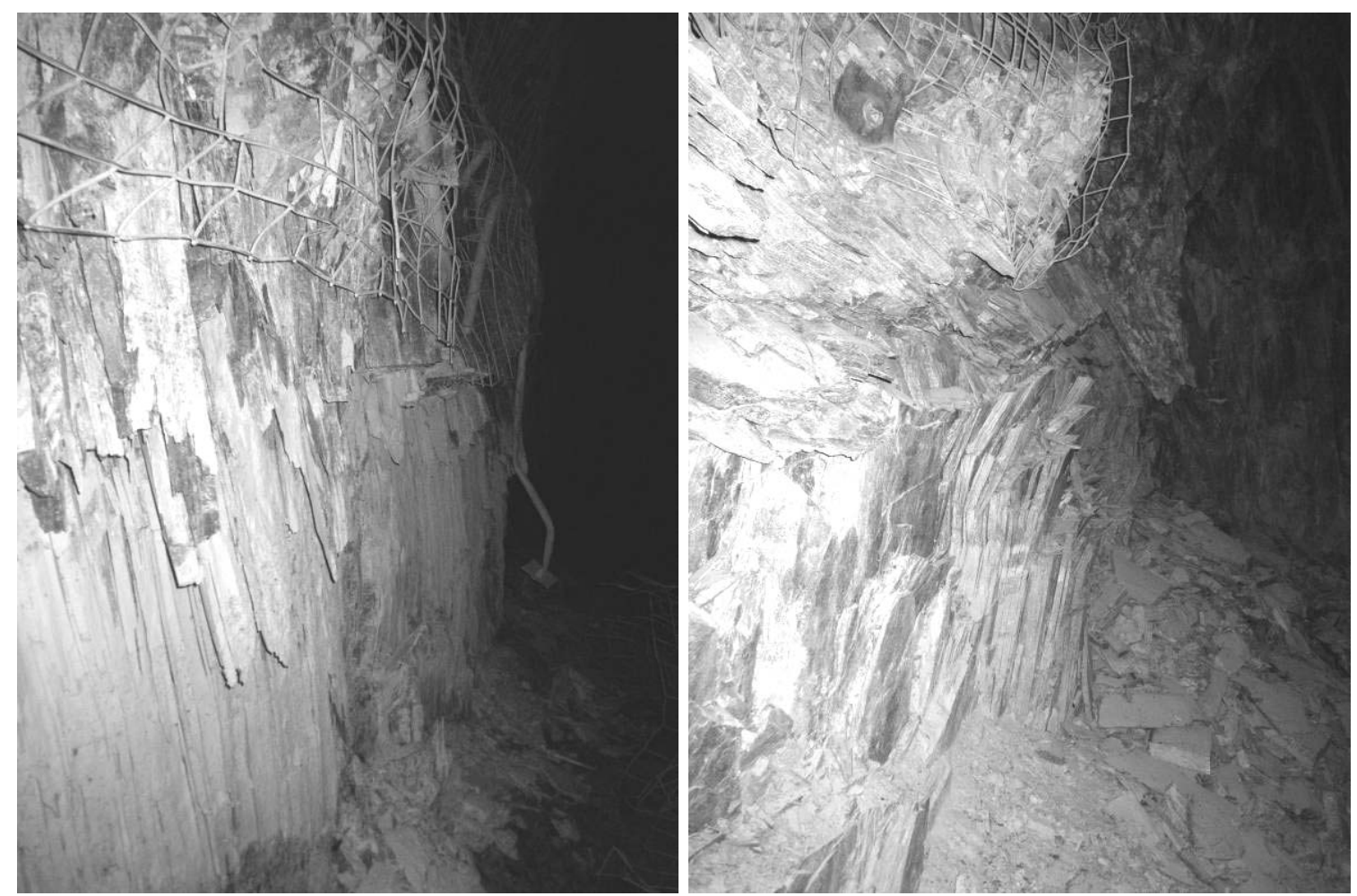

Figure 4 Variations in squeezing severity in similar rock conditions, at varying depths: (left) low stress - minor squeezing at $1,200 \mathrm{~m}$; (right) high stress - severe squeezing at $2,500 \mathrm{~m}$

In situ stress orientation was found to be of relatively low importance for the buckling foliated rock that resulted in squeezing. This is attributed to the fact that stress redistribution around the drifts results in axial loads on the foliation planes.

\subsection{Angle of interception}

Field observations at Laronde support the hypothesis that the angle of the drift walls, with respect to the orientation of the foliation has a significant influence on the level of squeezing. This was quantified by the angle of interception $\psi$ which was defined as the angle between the normal to the foliation planes and the normal to the wall of interest, Figure 5. The influence of the angle of interception was evident at $2,150 \mathrm{~m}$ depth. As shown in Figure 6 there was little evidence of squeezing when the foliation was perpendicular to the drift orientation, relatively more severe at 45 degrees and extreme when foliation was parallel to the drift. 


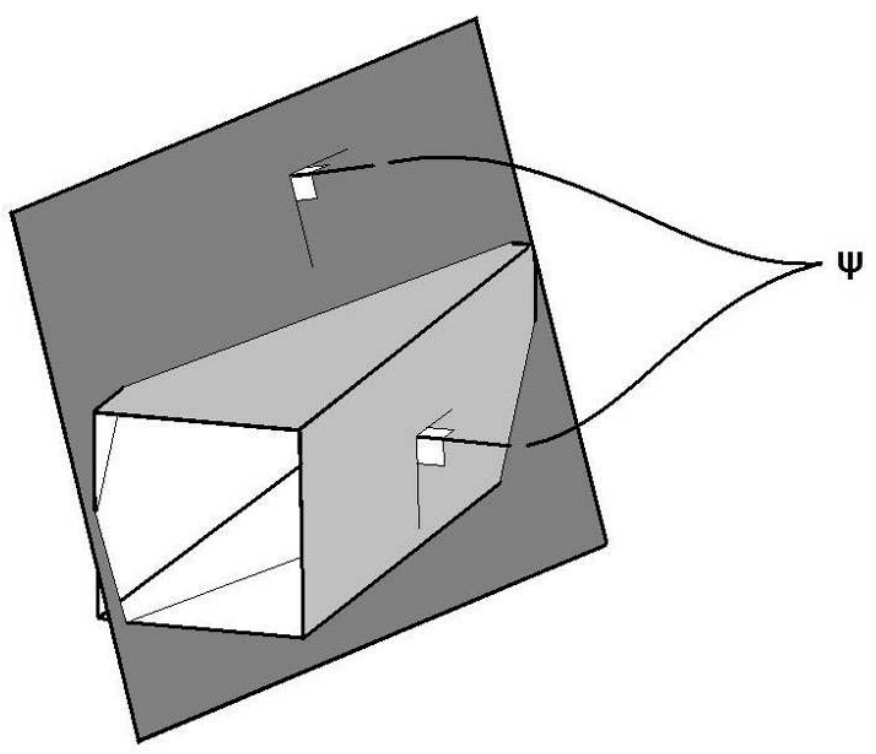

Figure 5 Definition of angle of interception $(\psi)$

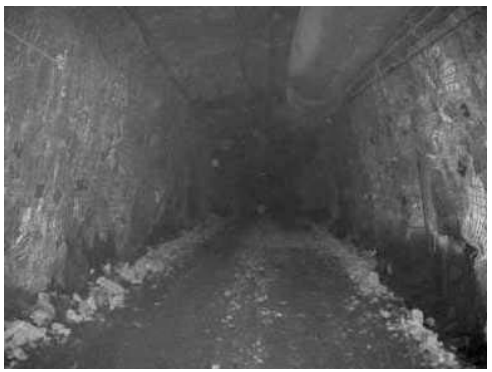

(a)

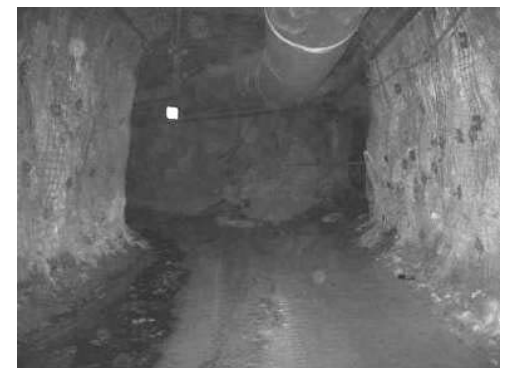

(b)

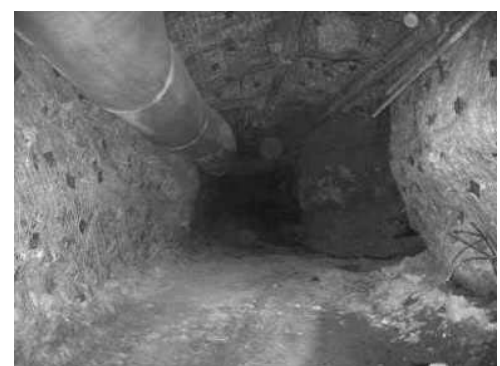

(c)

Figure 6 Variations in squeezing severity in three locations less than $100 \mathrm{~m}$ apart at 2,150 m depth: (a) perpendicular - no squeezing; (b) 45 degrees - minor or no squeezing; (c) parallel severe squeezing

In drifts developed sub-parallel with respect to foliation, it was recognised that irrespective of the employed support system it was difficult to maintain the drifts open and it was necessary to resort to regular rehabilitation to keep the drifts functional. The mine undertook a review of drifts developed at varying angles with regards to foliation and where different levels of squeezing were witnessed. This audit took into consideration the induced stress levels around each drift (approximately 30 separate locations). The results of this survey are presented in Figure 7 where the $\mathrm{x}$-axis is the intersection between the drift and foliation. The $y$ axis is an empirical assessment of the performance of the audited drifts. At the top of the axis were drifts that required multiple rehabilitation to keep open, followed by rehabilitation, and different degrees of squeezing. This analysis resulted in 'critical' drift orientations for which haulage drifts would require less rehabilitation.

It is interesting to note that both under very high and high stress conditions there are three unambiguous design domains. The squeezing potential is higher at shallower angles up to 25 degrees or when the foliation planes are near parallel to drift walls. This corroborates observations by Klein (2001) that overbreak and loosening around a tunnel was much more extensive when the strike of steeply-dipping joints or shear bedding planes was within about 25 degrees of the tunnel axis.

When the intersection angle between drift alignment and foliation was from 25 to 40 degrees, a very steep curve outlines a transition zone, whereby the squeezing potential of drifts decreases significantly. Finally, at angles exceeding 40 degrees, most headings exhibited only minor squeezing. 


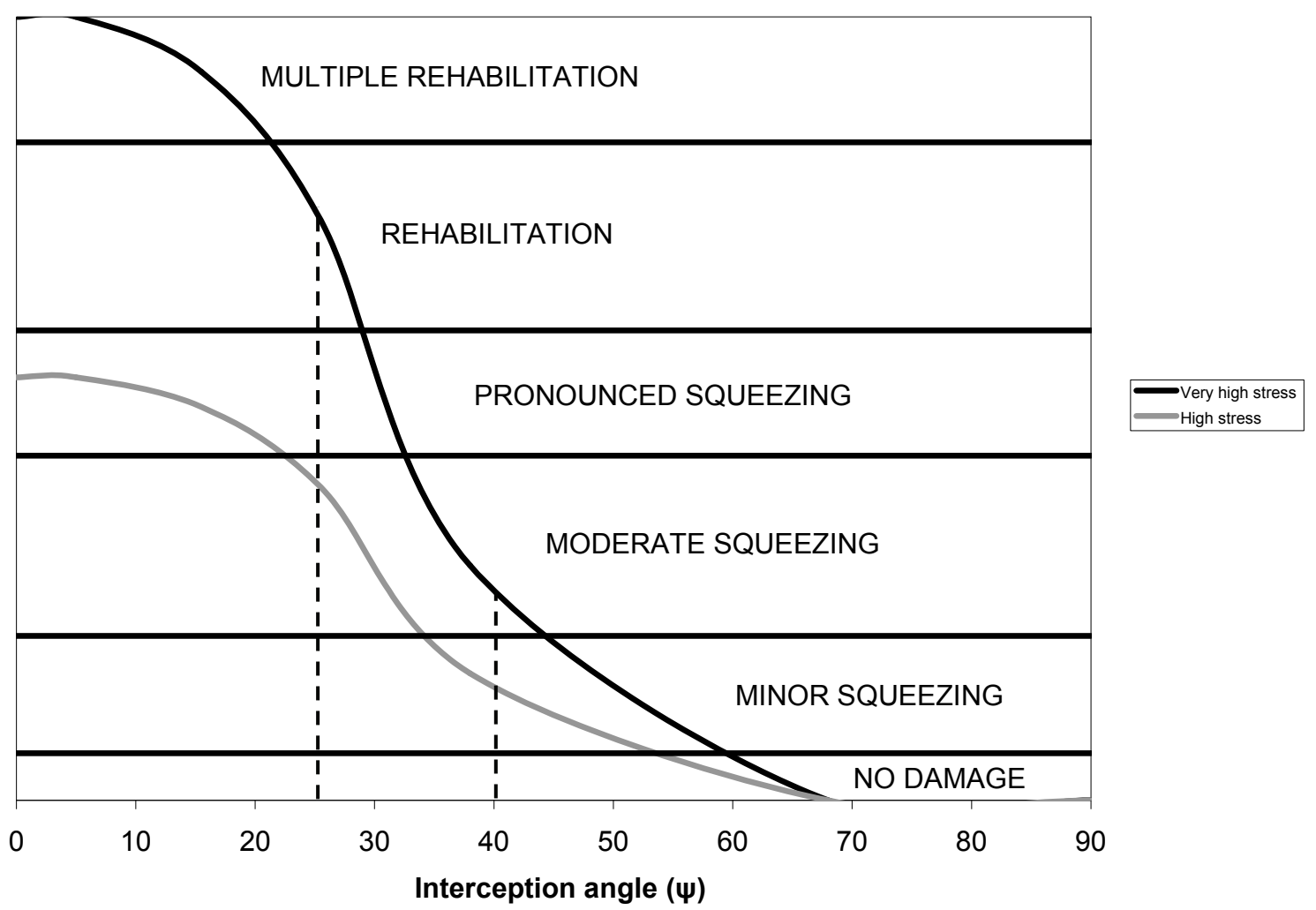

Figure 7 Preliminary interpretation of squeezing at LaRonde (after Mercier-Langevin, 2005)

This orientation phenomenon is supported by a mechanistic analysis. Auto confinement of foliation planes increases significantly when the angle between the normal to the free face and the normal to the foliation increases. It is recognised that even a small confinement is sufficient to inhibit buckling failure of the slabs. Kazakidis (2002) demonstrated that a relatively low confining pressure could be sufficient to prevent buckling failure of bedding planes.

\section{Squeezing ground index}

In order for squeezing ground conditions to develop extensive closure of an excavation must take place implying that induced stresses must exceed the rock strength. It follows that stresses need not be very high for squeezing to occur for low strength rock. Conversely, even relatively competent rock can be prone to squeezing, if stress is high enough. Figure 8 is an extension of Table 1 by Potvin and Hadjigeorgiou (2008), by introducing the influence of stress. Furthermore, it plots data from other mines experiencing squeezing. The wide range of conditions encountered at LaRonde result in the presented ellipse, whereby squeezing conditions can range from minor (drifts developed at a favourable angle to foliation, in 'fresh' and lightly foliated ground, near surface) to extreme (drifts at a shallow angle to foliation, in highly stressed altered and foliated rock). Mines for which case studies were available in literature were added on the matrix, but as the published data is often limited to snapshots, they are represented as dashed ellipses. 

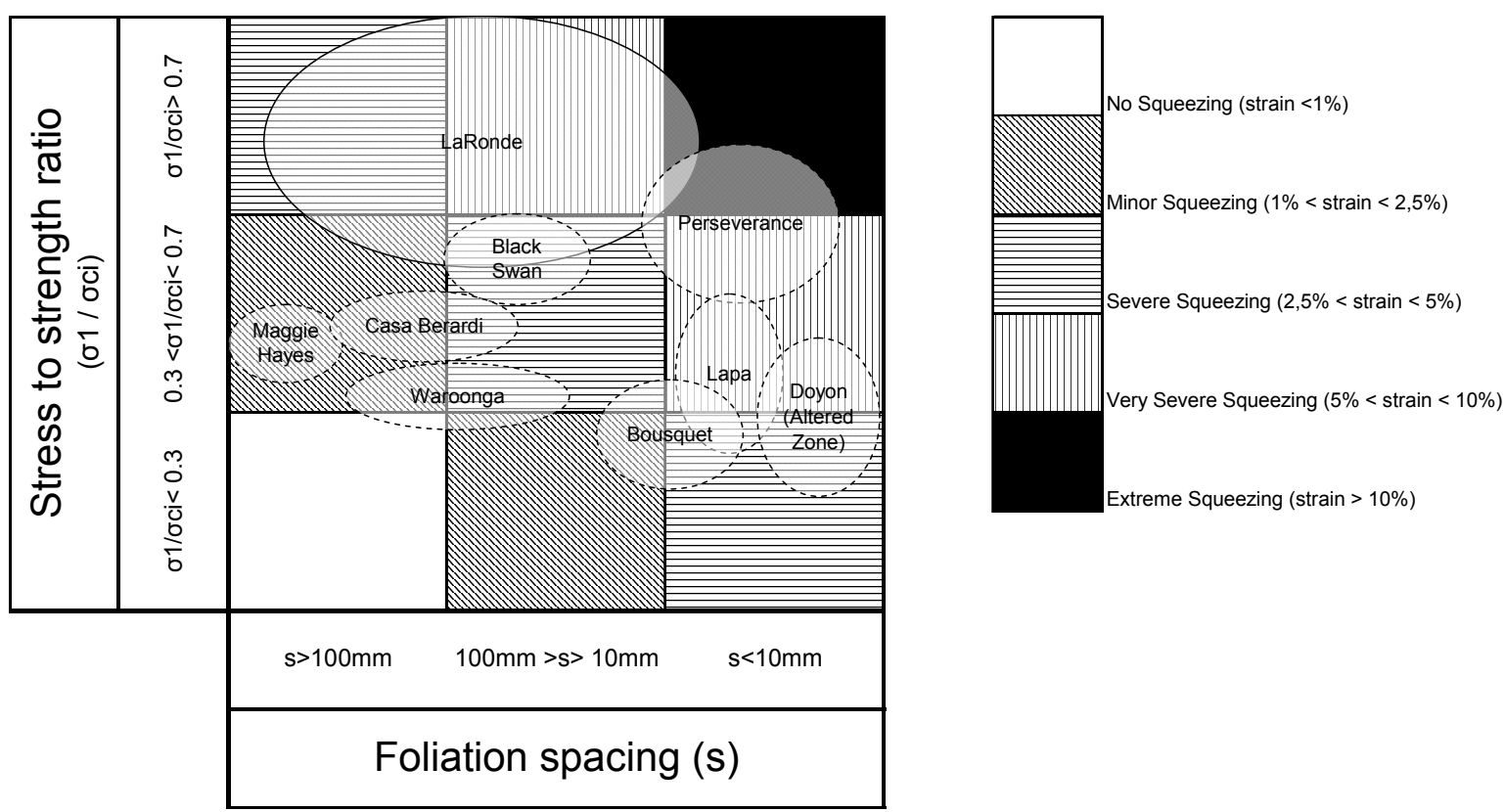

Figure 8 Foliation spacing - stress matrix to predict areas of squeezing

At LaRonde the influence of drift orientation with regards to foliation is probably the most important factor on the resulting squeezing severity in hard rock. These observations were used to develop a series of prediction matrices, Figure 9. It was observed that as the angle of interception ( $\psi$ ) increases (Figure 9), squeezing becomes almost purely stress-driven, and foliation spacing has little to no effect on the squeezing potential of the rock. This provides an interpretation of the different squeezing case studies at LaRonde.

$0^{\circ}<\psi<25^{\circ}$

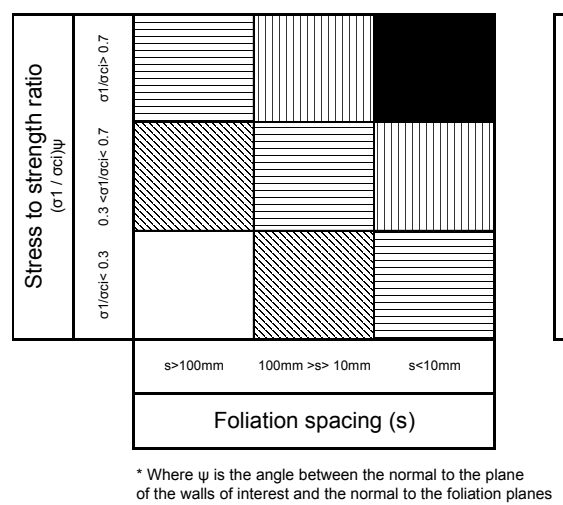

$25^{\circ}<\psi<40^{\circ}$

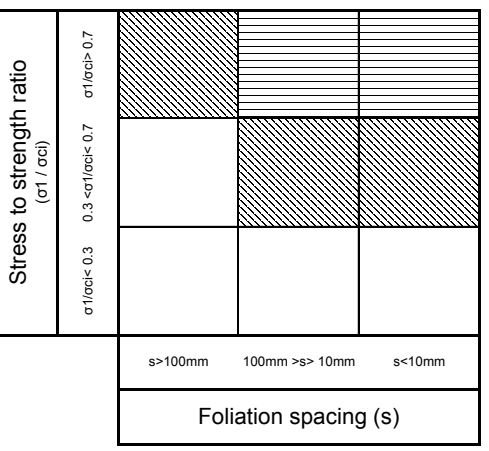

$40^{\circ}<\psi<90^{\circ}$

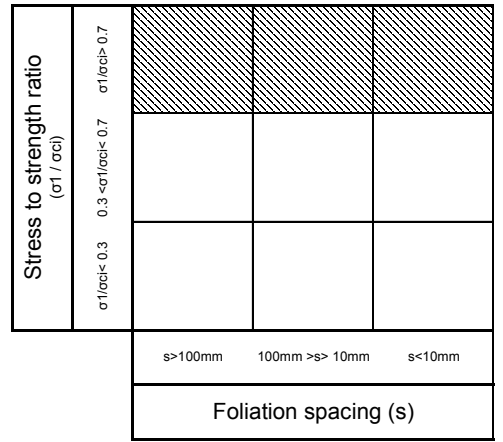

Figure 9 Different squeezing matrices for varying angles of interception

\section{Discussion}

The developed matrices are based on observations at several mine sites but have been calibrated based on observations at the LaRonde Mine. The prediction of squeezing severity does not take into consideration the choice of support system. Although it has been noted that different support systems may be more successful in managing tunnel convergence, typical support configurations in hard rock mines are currently unable to prevent or even significantly reduce tunnel deformation under extreme conditions.

The second issue that has to be addressed is whether the developed design matrix is applicable to other mine sites. The authors would suggest that the matrix can be potentially applied to sites where the rock mass is defined by foliation and consequently behaves in an anisotropic fashion under stress.

Lower bounds for foliation spacing and UCS values whereby the matrices become inapplicable need to be defined. The authors tentatively set those values at approximately $15 \mathrm{MPa}$ for UCS and less than $1 \mathrm{~mm}$ for 
foliation spacing. Below these threshold values, the behaviour of the rock becomes more complex. Under these conditions, the influence of anisotropy in foliated rocks becomes less critical, potentially limiting the range of applicability of the matrices.

Provided that the constitutive behaviour or foliated hard rock could be modelled reliably, numerical modelling could be an invaluable tool to validate the matrices, and identify other potential key parameters affecting squeezing ground in hard rock.

\section{Conclusions}

A significant number of hard rock mines in operation around the world have to manage problems associated with squeezing conditions. For these mines, maintaining excavations open and operational is difficult and often results in considerable investment in rock reinforcement and support but also in time-consuming and sometimes hazardous scaling and rehabilitation.

This paper reports on the development of a Hard Rock Squeezing Index for underground mines based on in situ observations from LaRonde, and from case studies reported from other mining operations. The Hard Rock Squeezing Index is based on the observed foliation spacing of the rock mass and the stress to strength of intact rock ratio. The index further incorporates the influence of excavation orientation with regards to structure in order to provide an indicator of squeezing potential. This index is a preliminary indicator of the squeezing potential of a rock mass and can potentially be useful at other hard rock mines experiencing squeezing ground conditions.

\section{References}

Aydan, Ö., Akagi, T. and Kawamoto, T. (1996) The Squeezing Potential of Rock Around Tunnels: Theory and Prediction with Examples Taken from Japan Rock Mechanics and Rock Engineering, Vol. 29 (3), pp. $125-143$.

Barla, G. (2002) Tunneling Under Squeezing Rock Conditions, Advances in Geotechnical Engineering and Tunnelling Vol. 5, pp. 169-268.

Barla, G., Bonini, M. and Debernardi, D. (2007) Modelling of tunnels in squeezing rock, 3rd Iranian Rock Mechanics Conference, October 2007, pp. 1267-1285.

Barton, N., Lien, R. and Lunde, J. (1974) Engineering classification of rock masses for the design of tunnel supports, Rock Mechanics, Vol. 6, No. 4, pp. 189-239.

Beck, D., Kassbohm, S. and Putzar, G. (2010) Multi-scale simulation of ground support designs for extreme tunnel closure, in Proceedings 2nd International Symposium on Block and Sublevel Caving (Caving 2010), Y. Potvin (ed), 20-22 April 2010, Perth, Australia, Australian Centre for Geomechanics, Perth, pp. 441-454.

Beck, D.A. and Sandy, M.P. (2003) Mine Sequencing for High Recovery in Western Australian Mines, in Proceedings 12th International Symposium on Mine Planning and Equipment Selection, 23-25 April 2003, Kalgoorlie.

Beer, G., Meek, J.L. and Cowling, R. (1981) Prediction of behaviour of shale hangingwalls in deep underground excavations, in Proceedings Fifth International Congress on Rock Mechanics, Balkema, Rotterdam, Vol. 2, pp. D45-51.

Einstein, H.H. (1996) Tunnelling in Difficult Ground - Swelling Behaviour and Identification of Swelling Rocks, Rock Mechanics and Rock Engineering, Vol. 29, No. 3, pp. 113-124.

Hoek, E. and Marinos, P. (2000) Predicting Tunnel Squeezing Problems in Weak Heterogeneous Rock Masses, Tunnels and Tunnelling International.

Hsu, S.C., Chiang, S.S. and Lai, J.R. (2004) Failure mechanisms of tunnels in weak rock with interbedded structures, in Proceedings SINOROCK2004 Symposium: Rock Characterization, Modelling and Engineering Design Methods, 18-21 May 2004, Yangtze River, China, International Journal of Rock Mechanics and Mining Science, Vol. 41, No. 3, Paper 2B-34.

Johnston, W. (1993) Soft rock engineering, in Comprehensive Rock Engineering, Vol. 1, Elsevier, pp. $367-393$.

Kazakidis, V.N. (2002) Confinement Effects and Energy Balance Analyses for Buckling Failure Under Eccentric Loading Conditions, Rock Mechanics and Rock Engineering, Vol. 35 (2), pp. 115-126.

Klein, S. (2001) An approach to the classification of weak rock for tunnel projects, in Proceedings Rapid Excavation and Tunneling Conference, San Diego, pp. 793-805.

Kontogianni, V., Tzortzis, A. and Stiros, S. (2004) Deformation and Failure of the Tymfristos Tunnel, Greece Journal of Geotechnical and Geoenvironmental Engineering, ASCE, pp. 1004-1013.

Lin, Y., Hong, Y., Zheng, S. and Zhang, Y. (1984) Failure Modes of Openings in a Steeply Bedded Rock Mass, Rock Mechanics and Rock Engineering, Vol. 17, pp. 113-119.

Mercier-Langevin, F. (2005) Projet de convergence des galeries - Phase 1: Consolidation de l'information disponible à la mine, Internal Memo, Agnico-Eagle Mines Ltd - LaRonde Division, Cadillac, Canada, 13 p. 
Mercier-Langevin, F. and Turcotte, P. (2007a) Expansion at Depth at Agnico-Eagle's LaRonde Division - Meeting Geotechnical Challenges without Compromising Production Objectives, in Challenges in Deep and High Stress Mining, Y. Potvin, J. Hadjigeorgiou and D. Stacey (eds), Australian Centre for Geomechanics, Perth, Chapter 21, pp. 189-195.

Mercier-Langevin, F. and Turcotte, P. (2007b) Evolution of ground support practices at Agnico Eagle's LaRonde Division: innovative solutions to high stress yielding ground, in Proceedings of the 1st Canada-US Rock Mechanics Symposium: Rock Mechanics - Meeting Society’s Challenges and Demands, E. Eberhardt, D. Stead and T. Morrison (eds), 27-31 May 2007, Vancouver, Canada, Taylor \& Francis, pp. 1497-1504.

Panet, M. (1996) Two Case Histories of Tunnel Through Squeezing Rocks, Rock Mechanics and Rock Engineering, Vol. 29, No. 3, pp. 155-164.

Potvin, Y. and Hadjigeorgiou, J. (2008) Ground Support Strategies to Control Large Deformations in Mining Excavations, The Journal of the Southern African Institute of Mining and Metallurgy, Vol. 108, July 2008, pp. 393-400.

Russo, G. (1994) Some considerations on the applicability of major geomechanical classifications to weak and complex rocks in Tunnelling, GEAM - Geoingegneria Ambientale e Mineraria, pp. 63-70.

Singh, B., Jethwa, J.L., Dube, A.K. and Singh, B. (1992) Correlation between observed support pressure and rock mass quality, Tunnelling and Underground Space Technology, Vol. 7, pp. 59-74.

Steiner, W. (1996) Tunnelling in squeezing rocks: case histories, in Rock Mechanics and Rock Engineering, Vol. 29, No. 4, pp. 211-246.

Struthers, M.A., Turner, M.H., McNabb, K. and Jenkins, P.A. (2000) Rock Mechanics Design and Practice for Squeezing Ground and High Stress Conditions at Perseverance Mine, in Proceedings MassMin 2000, G. Chitombo (ed), 29 October to 2 November 2000, Brisbane, Australia, Australasian Institute of Mining and Metallurgy, Melbourne, pp. 755-764.

Tyler, D.B. and Werner, M. (2004) A case study of ground support improvement at Perseverance Mine, in Proceedings Fifth International Symposium on Ground Support, Ground Support in Mining and Underground Construction, E. Villaescusa and Y. Potvin (eds), 28-30 September 2004, Perth, Australia, A.A. Balkema Publishers, London, pp. 53-63.

Wang, C., Wang, Y. and Lu, S. (2000) Deformational behaviour of roadways in soft rocks in underground coal mines and principles for stability control, International Journal of Rock Mechanics and Mining Sciences, Vol. 37, pp. 937-946.

Yassaghi, A. and Salari-Rad, H. (2005) Squeezing rock conditions at an igneous contact zone in the Taloun tunnels, Tehran-Shomal freeway, Iran: a case study, International Journal of Rock Mechanics and Mining Sciences, January 2005, Vol. 42, No. 1, pp. 95-108. 